\title{
O cuidado como ética e a ética do cuidado a partir de uma situação de recusa alimentar do bebê na creche
}

\section{Les soins en tant qu'éthique et l'éthique des soins à partir d'une situation de refus alimentaire du bébé dans la garderie}

\author{
Núbia Aparecida Schaper Santos ${ }^{1 *}$, Ilka Schapper Santos², Vanessa de Almeida Stigert ${ }^{3}$
}

\begin{abstract}
RESUMO
Este trabalho tem por objetivo discutir a creche como espaço importante para a constituição psíquica do bebê e problematizar o cuidado como ética a partir de um estudo de caso que envolve a recusa alimentar de um bebê de 14 meses no período de inserção na instituição. Trata-se de um bebê com histórico de recusa alimentar. Os dados apresentados foram produzidos durante sessão reflexiva realizada para professoras de uma creche conveniada do município de Juiz de Fora/MG, durante o segundo semestre do ano de 2019 e que tinha como principal objetivo problematizar as relações de poder e cuidado entre professoras e bebês na referida instituição. A partir do caso, pretendemos problematizar a creche como um espaço coletivo, que precisa se voltar para as particularidades de cada bebê, na sua constituição psíquica, incluindo nessa discussão o risco e o sofrimento psíquico.
\end{abstract}

Palavras-chave: Bebês; Creche; Cuidado

\section{ABSTRACT}

Ce travail vise à discuter de la crèche comme un espace important pour la constitution psychique du bébé et à problématiser le soin comme une éthique à partir d'une étude de cas impliquant le refus de nourrir un bébé de 14 mois pendant la période d'insertion. dans l'établissement. C'est un bébé avec des antécédents de refus alimentaire. Les données présentées ont été produites lors d'une séance de réflexion organisée pour les enseignants d'une garderie affiliée de la ville de Juiz de Fora/MG, au cours du second semestre de 2019, dont l'objectif principal était de problématiser les relations de pouvoir et de soins entre les enseignants et les bébés. dans l'école, ladite institution. A partir du cas, nous entendons problématiser la crèche comme un espace collectif, qui doit se tourner vers les particularités de chaque bébé, dans sa constitution psychique, incluant dans cette discussion le risque et la souffrance psychique.

Resumé: Bébé; Crèche; Soin

\footnotetext{
${ }^{1}$ Programa de Pós-Graduação em Educação - Universidade Federal de Juiz de Fora/MG. E-mail: nubiapsiufjf@gmail.com

${ }^{2}$ Programa de Pós-Graduação em Educação - Universidade Federal de Juiz de Fora/MG.

${ }^{3}$ Programa de Pós-Graduação em Educação - Universidade Federal de Juiz de For a/MG.
} 


\section{INTRODUÇÃO}

Este trabalho tem por objetivo discutir a creche como espaço importante para a constituição psíquica do bebê - que implica pensar seu endereçamento no campo do outro - e problematizar o cuidado como ética a partir de um estudo de caso que envolve a recusa alimentar de um bebê de 14 meses no período de inserção na instituição.

Por meio de estudos e pesquisas, sabemos que a creche é um dispositivo institucional importante em um país com muitas desigualdades econômicas e sociais e que permite à mulher inserção no mercado de trabalho. Contudo, enfrentamos a necessidade de problematizar a relação cuidar-educar diante do paradoxo que é pensar a constituição subjetiva do sujeito em um espaço coletivo.

Juiz de Fora/MG possui uma rede de creches conveniadas com a prefeitura para o atendimento educacional de bebês e crianças de 4 meses a 3 anos e 11 meses de idade. Por não possuir uma rede direta de gestão dessas creches, a opção do município é a realização de convênios com instituições comunitárias e filantrópicas sem fins lucrativos, que passam a ser prestadoras desse serviço para o município (Santos, Rezende, Araújo, 2018).

A natureza do trabalho com os bebês na creche desenvolve-se em relação de complementaridade com as práticas educativas e de socialização desenvolvidas pelas famílias. O atendimento prestado à comunidade é em tempo integral, de $7 \mathrm{~h}$ às $17 \mathrm{~h}$. A rotina institucional está organizada conforme a descrição do quadro a seguir, retirado do Projeto Político Pedagógico da creche:

07:00 às 08:15 - Recepção das crianças/ contato com as famílias/ primeira mamadeira para as crianças que necessitam/ Lanche no refeitório; 08:15 às 08:45 - Rodinha; 08:45 às 09:30 Banho de sol/ Recreação/ Desenvolvimento do planejamento/Projetos; 09:30 - Suco; 09: 30 às 10:30 - Banho; 10:20 às 10:40 - Almoço; 10:45 - Escovação dos dentes; 11:00 às 13:30 Repouso; 13:30 às 14:00 - Saída do repouso/Troca de fraldas e banho se necessário; 14:00 às 14:30 - Alimentação dos bebês - mamadeira para os que necessitam (BI)/ Lanche no refeitório; 14:30 às 15:20 - Desenvolvimento do planejamento/Projetos; 15:20 - Higiene das mãos e rosto; 15:30 - Jantar no refeitório; 16:00 às 17:00 - Higienizaçãol Troca de roupas- banho se necessário/Saída das crianças.

Durante o processo de observação na creche foi possível notar que a rotina estabelecida é executada de forma precisa, acompanhando os horários estabelecidos no quadro de rotina para início e término das atividades.

Olhar para a rotina estabelecida e vivenciada na instituição nos faz refletir sobre algumas questões. Acreditamos que a creche é lugar de cuidado, referência e laço entre professoras e bebês 
e que tem um papel mais amplo. É lugar de encontros/desencontros, ausências/presenças, de produção de subjetividades. A isso, devemos lembrar de Spitz como "primeiro a identificar, nas condições institucionais, a qualidade dos cuidados como fato essencial, no sentido do investimento da relação, determinante, não apenas da saúde psíquica, como também muito simplesmente da sobrevivência" (Crespin, 2016, p. 12). Como é possível cuidar de seis a doze bebês, com ajuda de uma auxiliar, sem ser a mãe ou alguém da referência familiar? Que possibilidade de constituir um olhar endereçado aos bebês em atividades descontinuadas a cada trinta minutos? Quais os efeitos disso para a vida psíquica dos bebês, considerando que professores e professoras podem ocupar a suplência da função parental?

Por meio das construções psicanalíticas de Freud e Lacan sabemos que as operações psíquicas sustentam o início da subjetividade a partir de um lugar Outro que não o organismo, o que imprime grande responsabilidade às creches, uma vez que essas operações podem fazer-se sem que sejam necessariamente pilotadas pelas mesmas pessoas que exercem a função materna e paterna. Ou seja, podem ser pilotadas pelo professor na creche. (KUPFER \& BRANDÃO, p. 276, 2014).

A psicanálise tem uma perspectiva peculiar para tratar das funções materna e paterna. Funções consideradas necessárias para a estruturação e desenvolvimento do psiquismo da criança. A partir do referencial psicanalítico temos conhecimento que não necessariamente a mãe e o pai biológicos são aqueles que vão exercer essas funções.

Segundo Crespin (2006) há distinção entre a parentalidade no campo biológico e simbólico, os pais são simbólicos e não somente biológicos. A autora declara que pode ocorrer de "outros" ingressarem na série simbólica de "pais" ou "mães" para o bebê, sem que isso seja consciente, nem que ocorra uma substituição dos pais biológicos, já que os elementos que estão em jogo são os representantes psíquicos. Nessa perspectiva, podemos pensar que os educadores podem entrar na série de pais simbólicos para um bebê. (SCHAPPER, 2018)

Kupfer e Brandão (2014) afirmam que as professoras do berçário podem participar desse campo do Outro para o bebê tendo, inclusive, condições de manter alguns elementos inerentes à função materna. As pesquisadoras afirmam que não se trata do exercício da função materna pela professora, mas de um trabalho em que se possam manter em andamento alguns eixos dessa função, de modo a "impedir que se rompa o laço mãe-bebê de forma precoce e antecipada" (p. 276). As autoras supracitadas têm adotado a expressão "função maternante" para nomear o trabalho das educadoras, fazendo uma distinção com a "função materna", que diz do trabalho materno, mas sem deixar de inscrever a marca de continuidade daquela em relação a esta (SCHAPPER, 2018). Como isso poderia operar na creche?

Dito isso, chamou a nossa atenção, durante a observação no contexto da creche, uma situação de recusa alimentar. Mariana, (nome fictício), com idade de 14 meses, i matriculada na creche pela mãe, que trabalha como diarista. Segundo a professora, a mãe de Mariana não 
insiste na introdução de novos alimentos, ficando sob responsabilidade da avó materna essa função. Segundo a mãe, a avó tem mais êxito. Na creche, Mariana frequentemente recusa a alimentação, o que produz na professora preocupação e exaustão. Os dados apresentados foram produzidos durante sessão reflexiva realizada para professoras de uma creche conveniada do município de Juiz de Fora/MG, durante o segundo semestre do ano de 2019 e que tinha como principal objetivo problematizar as relações de poder e cuidado entre professoras e bebês na referida instituição.

Então, eu acho assim, se ela tá aqui comigo, ela fica oito horas comigo, ela tem que se alimentar, ela não gosta de lanche, ela não gosta de fruta, então o almoço e a janta ela tem que comer, por isso que eu fico no pé dela e isso não quer dizer que eu seja brava, que eu não esteja dando carinho, é porque eu preciso ver essa menina saudável! Que seja de segunda a sexta, porque eu preciso ver, porque em casa não adianta! Ela não come! (CONCEIÇÃO, SR I, p. 5 e 6).

A fala da professora revela uma preocupação, que está circunscrita à realização de uma tarefa. Há uma ideia sublinhada pela professora que ver a menina bem, é vê-la alimentada e de que ensiná-la a fazer isso se sobrepõe ao desejo da bebê de não querer o alimento. Por vezes, foi presenciado momentos de conflito e de uso da força física e verbal para se alcançar o objetivo, com presença de vômito pela menina.

Igual hoje, hoje eu fiquei com a Mariana no almoço até quase meio dia! Eolha, gente, dezembro, vocês acham que a Mariana vai aprender a comer? Não vai! Não vai, infelizmente, é como a Elisa disse, como eu vou deixar uma criança o dia inteiro sem comer? Ela não come nada em casa, ela não come nada que se sirva no almoço. Aí você acha que minha cabeça fica como? Você acha que eu não tenho que gritar com ela?! Tudo bem que é errado, mas como eu vou deixar aquela menina com aquele corpinho que ela tem, eu tenho medo dela passar mal, eu tenho medo daquela menina desmaiar se ela ficar sem comer! Infelizmente eu falo, falo com a mãe e a mãe nada. Então eu também perco minhas forças, eu também fico nervosa mesmo! Entendeu? (CONCEIÇÃO, SR III, p. 41 e 42).

Couvert (2020), em seu livro intitulado A clínica pulsional do bebê, nos alerta que os distúrbios alimentares, muitas vezes, trazem a ideia de algo que "não é bom", que aquele que recusa é mau. A autora explica que

[...] não levamos em conta o que realmente está em jogo e que é da competência do campo oral, pois o bebê pensa de outra maneira. Basta se deixar ensinar e aprendemos a entender essas recusas alimentares de um modo totalmente diferente. Desviar a boca, apertar os lábios, cuspir, até regurgitar, ou, ao 
contrário, se deixar empanturrar e nunca ficar saciado, se tornam respostas singulares do recém-nascido quando ele se depara com trocas nutricionais que não estão "temperadas" com esse pouco a mais de prazer (COUVERT, 2020, p.82).

Diante disso nos interrogamos: Quais marcas poderiam ser desenhadas pela relação de Mariana com a professora? O que significa o investimento da professora e, paradoxalmente, a recusa de Mariana a esse investimento? Que experiência no corpo dessa bebê se coloca a partir de situações como essa no contexto da creche? Que tipo de manejo e cuidado a professora pode ter para possibilitar outra relação dessa bebê com o alimento que não seja apenas pela via da força física (como aconteceu) ou violência simbólica para garantir a alimentação dela? Como poderíamos ler essa recusa alimentar e como poderíamos traduzir, da parte de Mariana, o que ela busca? Quais demandas esse bebê dirige ao outro? Observamos que os momentos de alimentação são momentos de tensão e cuidado do/com o corpo físico e psíquico dos bebês, de incômodos e questionamentos que atravessam fortemente a relação das professoras com eles.

A partir do caso, pretendemos problematizar a creche como um espaço coletivo, que precisa se voltar para as particularidades de cada bebê, na sua constituição psíquica, incluindo nessa discussão o risco e o sofrimento psíquico (Wanderley; Gille, 2018; Crespin, 2016).

Crespin (2013) menciona que um profissional ao se deparar com bebês pode ocupar "o lugar de outro no lugar de Outro" e isso significa que, há, de acordo com Oliveira e Cohen (2017), a necessidade do "outro" "[...] enquanto sujeito que dará suporte para a existência do bebê no plano físico e afetivo" (p. 9). Esta relação do bebê com o outro é uma relação dialética de alienação e desejo e possibilita, segundo os autores mencionados recentemente, que o bebê busque no outro e na relação estabelecida, tornar-se sujeito, estruturando-se a partir da linguagem. Pode-se afirmar que o suporte do outro é fundamental para que o bebê se "humanize" e tenha, a partir da linguagem e do outro, contato com o grande Outro primordial.

Ao saber da importância do outro na relação com os bebês, a psicanalista Crespin expôs em sua obra quatro variantes ou representações em que um profissional pode adotar com bebês, são elas: "O outro arcaico; O outro ausente; O outro operador e o Outro que se prepara para o encontro, abrindo-se a dialética do desejo" (p.78). O outro arcaico se dá quando a criança é posta em um lugar narcísico de uma relação possessiva e exclusiva com a criança. Nessa relação é comum existir um excesso de amor e zelo ou um desprezo e descuido. $\mathrm{O}$ outro ausente surge quando se proporciona à criança um lugar de cuidados e técnicas estritamente profissionais. $\mathrm{O}$ atendimento pode ser atencioso, mas tem um cunho anônimo em que o responsável faz o mesmo atendimento e relação com qualquer outra criança. O outro operatório diz respeito à reprodução de métodos utilizados para o melhor desempenho da relação profissional. Essa relação traduz um envolvimento baseado em palavras destinadas às crianças que se tornaram, muitas vezes, mecânicas e que possuem o objetivo educativo e metodológico. O outro disponível para o 
encontro e que possibilita a dialética do desejo é àquele que corresponderia "ao lugar fálico" (p.81). Tal posicionamento diz respeito a uma posição que oportunize a criança um investimento simbólico e que tenha, por parte do profissional, um distanciamento de possíveis impressões e projeções. Crespin (2013) ressalta que nessa perspectiva o profissional pode vir a estabelecer um vínculo com a criança em que

“A criança não é obrigada a se assemelhar ao adulto nem a preencher as suas expectativas presentes, ou futuras; A criança pode se ligar a outras pessoas por razões próprias e o adulto deverá respeitar; A criança deixará o adulto sem que ele possa 'recolher os frutos' de seu investimento, nem reclamar 'suas dívidas', em termos de reconhecimento da parte da criança” (p.82).

Portanto, de acordo com a variante do outro disponível para o encontro e que possibilita à dialética do desejo, a criança é protegida de toda a antecipação de conceitos e determinações e tida como um sujeito único, com possibilidades, e um psiquismo em desenvolvimento. É assumindo a posição do outro disponível para o encontro e que possibilita à dialética do desejo, que o profissional conseguirá, possivelmente, se atentar para a riqueza de acontecimentos que ocorre com os bebês no campo psíquico.

Marie-Christine Laznik (2004) diz do olhar do Outro primordial como constitutivo do eu e da imagem do corpo. Trata-se de quando a criança se dirige ao outro que a carrega e pede a confirmação, pelo olhar, do que ela percebe no espelho como definição de uma imagem, de um domínio ainda não conquistado. Esse tempo de imagem ao espelho dará ao bebê um sentimento de unidade, de pertencimento e será a base de relacionamento com os outros. Esse olhar do Outro primordial é, de uma forma particular, um investimento libidinal do outro que permite a criação de uma ilusão antecipatória de um bebê real que poderá advir da relação com o Outro e com a linguagem. Laznik (2004) destaca também que é importante o olhar do Outro junto as muitas observações que são feitas do bebê, os balbucios, o choro e outras manifestações constantes realizadas por eles. Laznik também diz que essas observações foram denominadas por Winnicott como a loucura das mães e alerta para a ausência desse olhar enquanto uma possibilidade de evidenciar problemas precoces na relação com o Outro. Essa ausência não se refere apenas ao olhar como ação de ver restritamente falando, mas é um olhar que vai além do sentido da visão, é um olhar de presença, um olhar repleto de atenção, comunicação, carinho, investimento libidinal, um olhar que vai ao encontro do que Crespin (2013) relata como o Outro que se prepara para o encontro, abrindo-se a dialética do desejo. Sobre isso Laznik (2004) menciona ainda que

\footnotetext{
"O olhar se opõe a visão em sua relação a noção de presença. Esta presença pode ser-me significada pelos dois globos oculares em minha direção, caso em que o olho seria mais o signo de um investimento libidinal do que o órgão responsável pela visão. Mas essa experiencia da presença pode se manifestar igualmente por uma voz" (p. 40).
} 
Desse modo, o olhar pode ser também efeito da palavra que, completa de desejo e no lugar do Outro, torna-se o olhar.

O caso discutido neste trabalho nos leva a pensar na necessidade de reorganizar a reflexão de cuidar-educar sobre outras bases epistemológicas, que não somente de uma perspectiva pedagógica, bases que possam dar subsídios aos educadores para compreenderem a relevância de seu trabalho junto à constituição psíquica dos bebês. Para que educadores possam se dirigir aos pequeninos com possibilidades de se fazer lugar, lugar do grande Outro primordial. Para que isso possa emergir no trabalho é imprescindível uma formação dos profissionais das creches que transcenda a discussão dos operadores pedagógicos e traga para a cena discursiva os elementos que darão subsídios a esses profissionais de operarem por meio de outra cena. Ao lado disso, há que se considerar a creche como lugar de escuta e de permanente reflexão sobre aquilo que está para além das necessidades evocadas pelo corpo "bio-pedagógico". E assim, a educadora que está às voltas com a recusa alimentar do bebê, como trouxemos aqui, poderá ter outros elementos para ler isso que aparece desse sujeito como, porque não dizer, uma forma de ele se enlaçar: pela recusa.

\section{REFERÊNCIAS}

COUVERT, Marie. A clínica pulsional do bebê. São Paulo: Instituto Langage, 2020.

CRESPIN, Graciela C. A emergência do sujeito no berçário institucional. In: BUSNEL, Marie - Claire e Melgaço, Rosely Gazire, Org(s.). O bebê e as palavras: uma visão transdisciplinar sobre o bebê. 1. Ed. - São Paulo: Instituto Langage, 2013 - p.74-83.

CRESPIN, G \& PARLATO OLIVEIRA, E. Projeto PREAUT. In: JERUSALINSKY, Alfredo (org). Dossiê Autismo. São Paulo: Instituto Langage, 2015.

CRESPIN, Graciela. À escuta de crianças na Educação Infantil. São Paulo: Instituto Langage, 2016.

KUPFER, M.C.M \& BRANDÃO. A construção do laço educador-bebê a partir da Metodologia IRDI. IN: Revista de Psicologia da USP, vol. 25, n.3, pp. 276-283, 2014. Disponível em: http://www.scielo.br/pdf/pusp/v25n3/0103-6564-pusp-25-03-0276.pdf. Acesso em: 22 ago. 2017.

LAZNIK, M. C. Poderíamos pensar em uma prevenção da síndrome autística? In D. B. Wanderley (Org.) A voz da sereia: o autismo e os impasses na constituição do sujeito. Salvador, BA: Ágalma, 2004.

LAZNIK, Marie-Christine. A voz da sereia: o autismo e os impasses na constituição do sujeito. Salvador: Ágalma, 2004. 
SANTOS, Núbia A. S., ARAÚJO, Viviam C. D., \& REZENDE, Wagner S. (2018). Identidade, docência e formação de professoras que atuam em creches: um diálogo com a pesquisa. Colloquium Humanarum. ISSN: 1809-8207, 15(3), 29-41. Recuperado de https://journal.unoeste.br/index.php/ch/article/view/2451

SCHAPPER, Ilka. No meio do caminho, o bebê. IN: JERUSALINSKY, Alfredo \&amp; BENTATA, Hervé (org). Dos primórdios à adolescência: desafios e perspectivas. São Paulo: Instituto Langage, 2020.

Recebido em: 10/01/2022

Aprovado em: 12/02/2022

Publicado em: 15/02/2022 